This item was submitted to Loughborough's Research Repository by the author.

Items in Figshare are protected by copyright, with all rights reserved, unless otherwise indicated.

\title{
Naoya Hatakeyama and the photographic representation of Post-Tsunami landscapes in Japan
}

PLEASE CITE THE PUBLISHED VERSION

https://doi.org//10.1386/jcca.3.3.355_1

\section{PUBLISHER}

(C) Intellect

VERSION

AM (Accepted Manuscript)

\section{PUBLISHER STATEMENT}

This work is made available according to the conditions of the Creative Commons Attribution-NonCommercialNoDerivatives 4.0 International (CC BY-NC-ND 4.0) licence. Full details of this licence are available at: https://creativecommons.org/licenses/by-nc-nd/4.0/

\section{LICENCE}

CC BY-NC-ND 4.0

\section{REPOSITORY RECORD}

Bohr, Marco P.. 2019. "Naoya Hatakeyama and the Photographic Representation of Post-tsunami Landscapes in Japan”. figshare. https://hdl.handle.net/2134/26027. 


\title{
Naoya Hatakeyama and the photographic representation of post-tsunami
} landscapes in Japan

Marco Bohr, Loughborough University

\begin{abstract}
This article investigates the role that art photography of in relation to the earthquake and tsunami that hit Japan in March 2011. The article focuses on an ethical and moral debate that emerged amongst Japanese photographers who questioned how the disaster and its aftermath can be, or should, be represented in a photograph. At the forefront of this debate was the photographer Naoya Hatakeyama whose personal connection to the region turned him into a quasi spokesperson for his profession. Through a close reading of his photographic works, the article situates post-tsunami photography in relation to wider photographic trends in Japanese visual culture.
\end{abstract}

\section{Keywords}

photography

art

representation

disaster

trauma

memory

\section{Introduction}


The earthquake and tsunami that hit Japan on the 11 March 2011 were a major turning point in Japanese society. The disaster was immediately followed by a man-made disaster - the nuclear crisis in Fukushima - which continues to unfold today and which some predict will unravel for many more decades to come. In any debate on 3.11, as this tragic event is commonly referred to in Japan, one must therefore distinguish between at least two interrelated yet also separate events: a natural disaster set in the past and outside of the control of man, as well as a man-made disaster set in the past, present and future. For the sake of clarity this article will largely focus on the natural disaster.

Another distinction needs to be made with regard to the type of photographs that I am referring to here: this article is not concerned with photojournalism - a discussion of which would exceed the scope of this article. Rather, my focus is on art photography, or photographic works produced within a contemporary art context. In Japan these two genres are occasionally distinguished on a linguistic level by referring to photojournalists (regardless of their gender) as kameraman, whereas art photographers are known as shashinka, derived from the Japanese word for photography shashin. The suffix $k a$ is associated with a level of expertise and artistic authorship more commonly associated with art photographers, and it is this group that I am referring to in this article.

3.11 had a profound impact on photographic discourses in Japan. Indeed, the event caused such a major turning point in Japanese society that two camps of photographers soon began to form in the aftermath: those who chose to travel to the affected region to embark on a photographic project, and those who consciously chose 
not to go to the region. Yet the boundaries between these two camps are actually much more blurred than they first appear. For instance, some photographers travelled to the region and ended up not taking any photographs at all, while others addressed the disaster from a more abstract point of view via visual allegories or metaphors even though they perhaps never entered the affected region as such. Either way, these strategies by art photographers are largely centred on a wider debate on ethics and morals, which I want to highlight in this article.

To do so I will mainly refer to the art photographer Naoya Hatakeyama, whose role in the debate, for the following reasons, is rather significant. First, Hatakeyama's status as widely respected photographer affords him a level of seniority within a wider community of photographers that precedes 3.11. Second, Hatakeyama was one of the very first photographers to travel to the region in order to produce a photographic project. Since then Hatakeyama's photographs of areas affected by the tsunami have been shown in several national and international exhibitions to wide acclaim. Third, and perhaps most importantly, Hatakeyama grew up in a town called Rikuzentakata, which would become known as one of the most badly affected towns that were hit by the tsunami. As a consequence of these factors, Hatakeyama has emerged as a key national and international figure in photographic discourses on 3.11. The respected culture magazine Geijutsu Shinchō described Hatakeyama as a ‘spokesperson’ for photographers whose work is concerned with 3.11 (Anon. 2011a). It is for these reasons outlined above that this article mainly refers to Hatakeyama's experience to establish a moral and ethical framework of this debate, before analysing his work from Rikuzentakata in more detail. 


\section{A question of ethics}

In an interview for the photography magazine Asahi Camera published in September 2011 Hatakeyama recounts what happened on the tragic day that Japan was struck by a massive earthquake and tsunami (Hatakeyama 2011a). As fate would have it, Hatakeyama was attending a meeting with fellow photographers in a Tokyo office building when the earthquake struck. When news about the tsunami broke soon after, Hatakeyama recalls how one of the photographers attending the meeting said that the disaster represents an opportunity to produce 'good photographs' (ii shashin). Puzzled by the notion of a 'good photograph' produced in the midst of a natural disaster, Hatakeyama recalls the following:

Even if he [the fellow photographer] could take a photograph of a car floating in front of him, and even if that extremely spectacular image actually is a 'good photograph' [ii shashin] in his eyes, and the viewer would recognize the value of the image instantly, what kind of 'goodness' is realized through such an image? (Hatakeyama 2011a: 76)

Hatakeyama's question points to a crucial binary consistently overshadowing the ethical debate on representations of the land affected by the tsunami: how can an artistic medium associated with beauty and aesthetics be used to depict the ugliness of a disaster that caused widespread destruction and countless deaths? (see also Tran 2015). This binaryism is further amplified with regard to art photography because, similar to a painter or printmaker, the photographer is engaged in an activity where 
the final outcome is an artwork (sakuhin, derived from the words 'make' and 'object'). This is another aspect that distinguishes the art photographer from the photojournalist whose main concern is not to produce a stand-alone artwork but rather to produce images that would accompany or illustrate the news event. The difference between one and the other might appear subtle, but it has profound effects on the ethical considerations when photographing the event.

For Hatakeyama, therefore, the ethical concern about producing a 'good photograph' also extends into another question: how can a photographer produce an image of a disaster with the intention of producing an artwork? (Hatakeyama 2011b). This concern has been voiced by another photographer, namely Kisei Kobayashi, who wrote the following:

I avoided going to the affected region [hisaichi]. Of course, I wanted take photographs. On the other hand, I did not want to turn that tragic event into my 'artwork’ [sakuhin]. (2012: 19-20)

In this context it is important to note that the notion of an artwork also implies a viewer seeing this artwork, such as in a gallery, museum or another form of cultural institution. There is therefore a tangible link between a photographer's pursuit, the artwork, and the artwork viewed outside of the context of the subject depicted by the photographer. The danger for art photographers is that the subject they have depicted becomes objectified once it is visually and conceptually framed as an artwork and shown within an art context. Further complicating matters is the widely held assumption that artworks form part of an artist's upward trajectory in the art world 
and can therefore be interpreted as a method for personal gain. Confronted with this ethical dilemma, Kobayashi, like many other photographers, chose not to go the affected region.

Others, like the photographer, Takashi Homma felt compelled to physically travel to the region, but not actually represent the disaster per se, but to find different ways to depict the disaster through visual allegories or metaphors. For his photobook Mushrooms from the forest (2011) Homma produced still-life photos of irradiated mushrooms. The rationale behind this photographic methodology is described by Homma in a symposium held in June 2011 as follows:

Photographers [shashinka] are like vultures: they go to the site and take photographs and then sell these to the media. Although there is a certain reality in those images, I think they went there after the event and merely look at that site [genchi] I try to think about the difference between watching the news and looking at the site while being there. (Homma 2013: 24)

Against this discursive backdrop, the choice whether photographers should or should not go to the region affected by the tsunami was a hotly debated subject in a variety of different media (for instance Ishikawa and Moriyama 2011; Moriyama 2011). Out of this debate emerged a keen consideration for the word hisaichi, in this context a land affected by the tsunami, and hisaisha, a people affected by the tsunami. The latter term is problematic in the sense that it seeks to address an entire segment of the population, many of whom felt that the term is too impersonal and stigmatizing (Goto 2013). Photographing or even objectifying those affected by the tsunami, as 
photographers at the time realized, would have merely confirmed this stigma through the visual regime of the photograph itself. In many ways, ethical and moral concerns burdened photographers to such an extent that some of them felt paralysed in light of what happened on 3.11. Yet on the other hand, it also opened up new opportunities for photographers to represent the disaster from an entirely new point of view. In the very least the above summary should exemplify that 3.11 had a significant impact on photographic discourses in Japan, shifting the debate towards moral and ethical considerations, as well as questioning the role of photography, and indeed the photographer.

\section{Naoya Hatakeyama's photographs of Rikuzentakata}

In the context of the moral and ethical debate outlined above, it is important to establish why Hatakeyama was one of the first photographers to depict the aftermath of the tsunami. Hearing about the destruction in his hometown Rikuzentakata, Hatakeyama returned immediately out of concern for his family. The house of his sister was severely damaged while the whereabouts of his elderly mother remained unknown. She too, like so many others in Rikuzentakata, tragically passed away in the disaster. The intention of Hatakeyama's return was to help and provide comfort to those close to him, which differs dramatically from the intention of photojournalists on assignment for a newspaper for instance. Over the ensuing weeks and months, however, and partially encouraged by his family, Hatakeyama began to photograph the affected region near his hometown. At this moment in time, Hatakeyama committed himself to a major shift in his career as an artist and photographer. Widely 
regarded as one of Japan's best-known art photographers, in the past Hatakeyama tended to photograph like a detached observer, looking at a subject from the outside. This is the case with his photographs depicting a former German coalmine in his book Zeche Westfahlen I/II Ahlen (Hatakeyama 2006) or his visual typology River Series (photography project from 1993/1994) where he photographed the underground canal system in Tokyo. His photographs are crisp, technically well executed and aesthetically composed depictions of man-made landscapes.

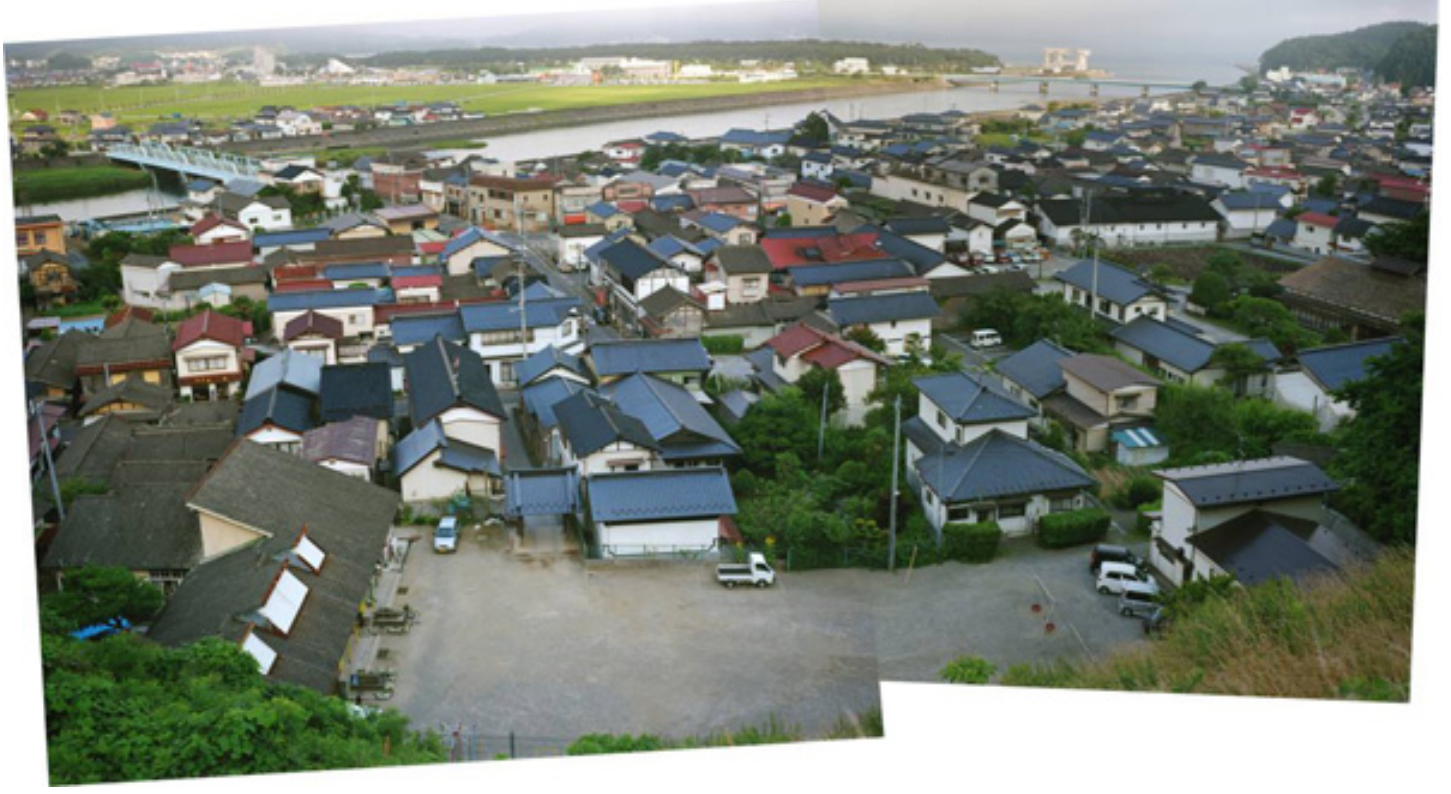

Figure 1: Naoya Hatakeyama, Rikuzentakata, July 2004. 


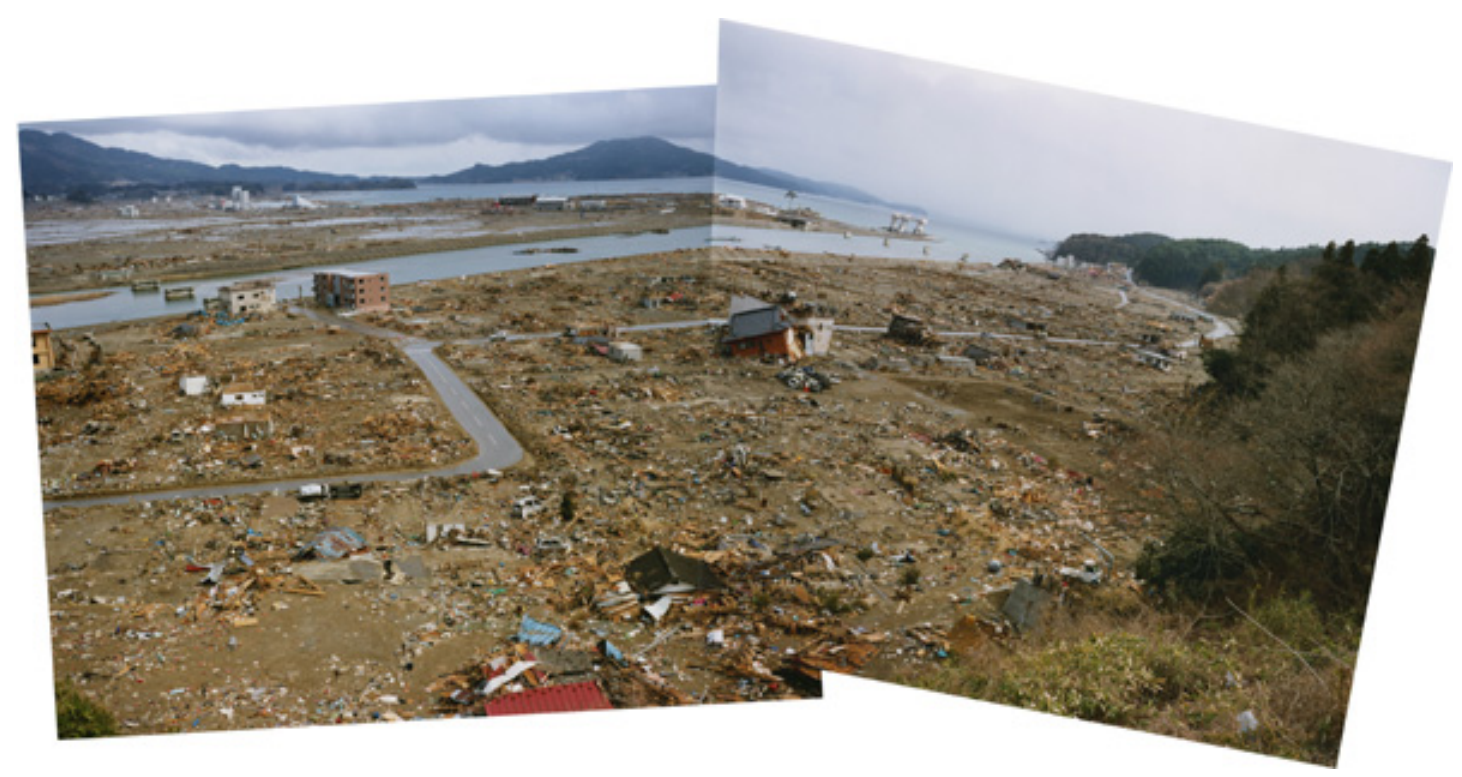

Figure 2: Naoya Hatakeyama, Rikuzentakata, April 2011.

While remaining true to his visual style explored in previous photographic projects, in his photographs of Rikuzentakata, however, Hatakeyama ventures into a subject matter that is far more personal. After all, Hatakeyama grew up in the town and on previous occasions would photograph it for his personal archive (Goldberg 2015). In July 2004, for instance, Hatakeyama photographed Rikuzentakata from an elevated viewpoint focusing on the town in the foreground while the sea is visible in the background to the image (see Figure 1). In order to depict the town from that particular vantage point and due to the narrow range of the lens, Hatakeyama chose to take two images that, once they have been merged with each other, present a wider perspective. Unlike the work of artists such as Andreas Gursky who use digital technology to create large-scale photographs produced out of many image components, Hatakeyama applies a much more intuitive photographic methodology as he simply merges two analogue images into one. The merging of images is purposely not seamless as one can clearly see that the montage is created by two separate images. In the context of Hatakeyama's oeuvre, this approach is rather 
unusual and perhaps it is an indication that this photographic montage was not primarily produced for public consumption in a gallery or in a book. The fact that this image was not published until after 2011 would support this theory. In addition to that, the splitting of the image also alludes to the fact that the subject matter is deeply personal and that the photographer's relationship to the subject is more complex and attaining the viewpoint of a detached observer is more challenging. The photographic montage alludes to the notion that photographs never produce one single 'truth' or 'reality', but rather that these realities are often more fragmented, complex and perhaps even contradictory.

On his return to Rikuzentakata in the aftermath of 3.11, in April 2011 Hatakeyama produced another photographic montage of his hometown. Even though this montage might have been taken with the same camera, with the same lens and from the same vantage point, it depicts an utterly different reality compared to the montage taken some seven years earlier: the urban landscape of the town has so dramatically altered that it bears very little resemblance to how it looked in the past. Rizukentakata has been completed flattened by the tsunami as only a small number of buildings were able to withstand the forces of nature. Hatakeyama has remarked that with no buildings or structures to anchor personal memories, and, vice versa, without access to these memories triggered by the buildings, his hometown looked much smaller than what he remembered (2011a: 77). There is, in other words, a very distinct rupture between how a place is remembered and how this place has now changed. In his post3.11 photographic montage of Rikuzentakata, Hatakeyama alludes to this friction between memory and reality by presenting the montage as much more flawed compared to the 2004 version: the seams of the two images are even more visible; the 
clouds in one image are darker than in the other; even the horizon line is distinctly crocked. In the context of 3.11, the photographic montage also assumes a new relevance: it alludes to the fact that the destruction of the tsunami is so unimaginably large that it cannot possibly be documented or presented through a single image. Here, the photographic montage also functions as a critique of the medium photography itself as Hatakeyama seemingly questions the validity of representation in relation to the disaster.

By presenting the two photographic montages from 2004 and 2011 side by side as a quasi-diptychs, Hatakeyama chose to question and complicate the role of photography even further. At first sight the diptychs can be seen to reinforce a temporal binary commonly applied by the news media which tended to focus on 'before' and 'after' photographs of the disaster. ${ }^{1}$ This form of binaryism also feeds into a larger philosophical discourse on nature and culture, which frequently pervades discussions on photography. In Hatakeyama's photographic montages on the other hand, the viewer is deeply implicated in the works as the images become more open to interpretation. As such, the viewer is also implicated in the temporal divide between the 'before' and 'after', whereas the destruction of the former is reinforced through the visual presentation of the latter. On one hand, images are merged, however crudely that may be, yet on the other hand the two photographic montages of 2004 and 2011 are also presented physically detached from each other. According to this complex presentation, there are no easy explanations as to what happened to Rikuzentakata. It is not simply a question of nature versus culture or a temporal 'before' and 'after', but rather these categories are informing one another through a nodal point manifested by the viewer looking at the photograph(s). 


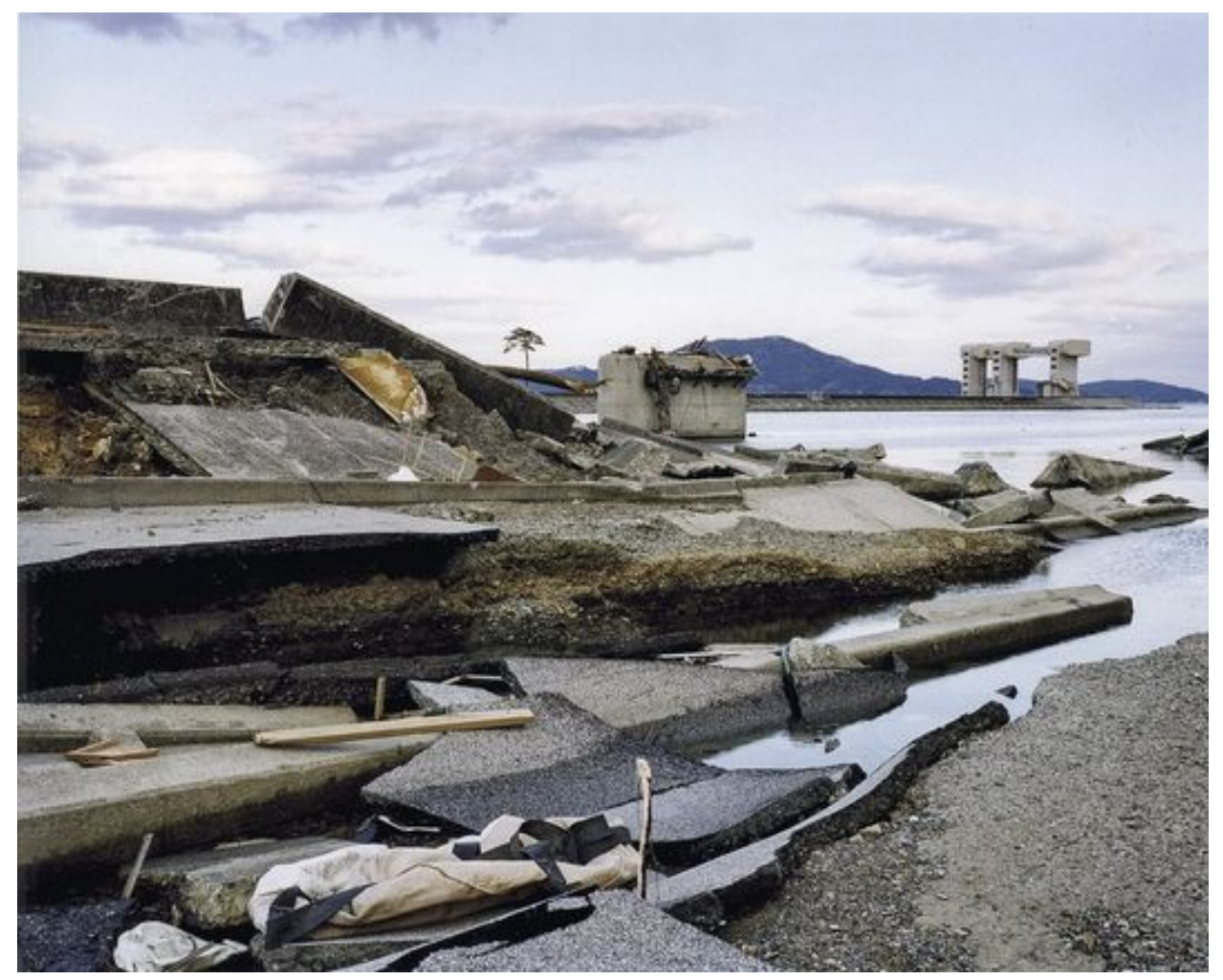

Figure 3: Naoya Hatakeyama, from the book Kesengawa (2013).

Like most art photographers in Japan, Hatakeyama tended to avoid taking pictures of people affected by the tsunami. This focus is reflected in the images he selected for a variety of magazines that published his work in the aftermath of 3.11 as well as his photobook Kesengawa, which was published in 2013 (Hatakeyama 2013). One exception, however, was a photograph of Hatakeyama's mother, taken by the photographer a few years before the tsunami hit the east coast of Japan (see Figure 4). Rather ominously, in the photograph the elderly woman is depicted as she is looking through a camera out towards the sea. Her body rests against a concrete bolder that is meant to break the impact of waves crashing into the coast, whereas her face is 
slightly obscured by the camera and the fact that she was depicted from a slight distance. The photograph further underlines a very distinct shift in Hatakeyama's practice that developed in the immediate aftermath of 3.11 as he begins to introduce subjects that are personal to him, even as personal as to include an image of his late mother. The invisible boundary between the detached observer and the subject that tended to exist in his previous body of work is now increasingly evaporating. By specifically introducing this very personal image in the book Kesengawa (2013), Hatakeyama invokes Roland Barthes’ classic book on photography, Camera Lucida, in which he describes the impact of seeing a photograph of his deceased mother (Barthes 1981). The tripartite relationship between the maternal, death and photography is cunningly alluded to in Hatakeyama's image. However, the fact that Hatakeyama's mother's face is partially obscured suggests that her presence in the image signifies the maternal in a more universal way. Hatakeyama does not as much represent his mother lost to the disaster, but rather he represents all loss of human life.

Hatakeyama is one of many renown Japanese photographers who either explicitly or implicitly reference the work of the so-called 'New Topographics' group of photographers. The term New Topographics is derived from the title of a highly influential exhibition held in 1975 at the George Eastman House in Rochester, New York, which focused on 'Photographs of man-altered landscapes' (Foster-Rice and Rohrbach: 2013). Artists participating in this groundbreaking exhibition include wellknown figures such as Lewis Baltz, Bernd and Hilla Becher or Stephen Shore, who have since gained great popularity in Japan. Their work can be characterized as straight-forward: both in the sense that their photographs are formally structured and composed, and also in the way that they are meant to be honest and truthful. 
Photographs are presented like emotionless matter-of-fact observations of the real world. The New Topographics have had a very large impact on photographic discourses in Japan, particularly with a generation of photographers who emerged in the 1980s and 1990s, such as Toshio Shibata.

Previous to 3.11, Hatakeyama's work can be seen to feed into this visual and philosophical discourse established by the New Topographics. Yet the inclusion of the photograph of his mother appears to question the photographer's ability to always remain emotionally detached from the subject matter depicted in the image. As such, Hatakeyama’s post-3.11 work represents an important break: not just from previous photographic projects but also more broadly from the large stronghold the New Topographics have had on photographic discourses in Japan. Here, Hatakeyama purposefully introduced a photograph to his body of work that is deeply 'personal', yet he does so in the context of a 'public' event visually consumed on TV, in the media and in photographs all across the world. In so doing, Hatakeyama points to the fact that the 'personal' cannot ever be wholly removed from the 'public'. Compared to other Japanese photographers such as Daido Moriyama or Naoki Ishikawa who also photographed the region affected by the tsunami, Hatakeyama's work stands out because it does not engage in the impossible task of trying to document the event, but rather it provides new ways of thinking about photography and its role in relation to disaster. Here, Hatakeyama has more in common with Toshi Fujiwara, whose mesmerizing essay film Mujin Chitai/No Man’s Zone (Fujiwara, 2012) provides a dense philosophical and self-reflective debate about the relationship between images, memory and disasters. ${ }^{2}$ 


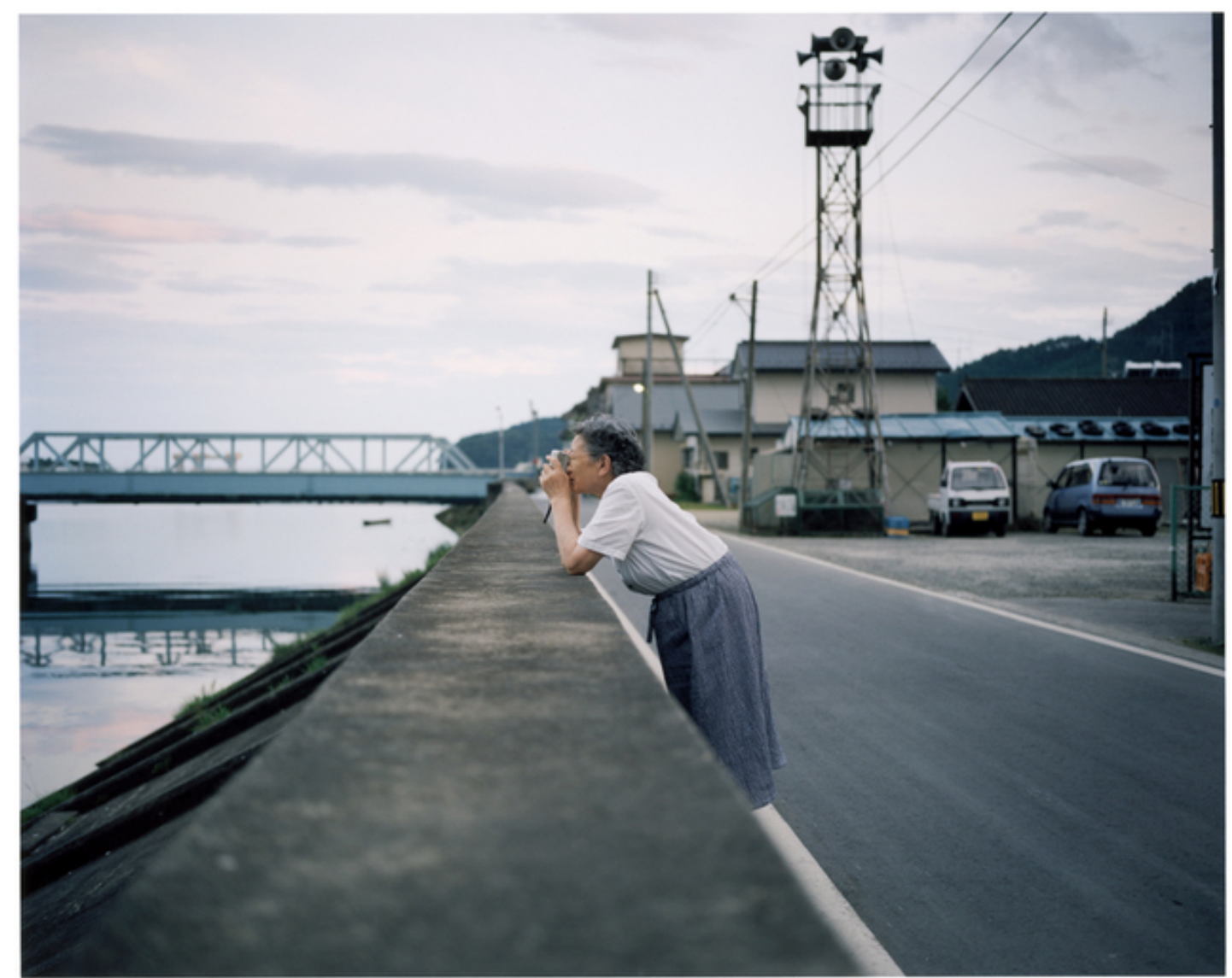

Figure 5: Naoya Hatakeyama, Kesengawa, 2003/08/23 (2013).

\section{Conclusion}

In her book Imaging Disaster: Tokyo and the Visual Culture of Japan's Great

Earthquake of 1923, the art historian Gennifer S. Weisenfeld argues that reactions to trauma are not just configured by society and politics, but that they are also informed by the representation of this trauma via photographs (Weisenfeld 2012). This argument appears to be particularly true for Japan, a country prone to be affected by natural disasters due to its vulnerable geographic location on the edge of the Pacific Plate, but also a key country with regard to the development of photographic technologies. The invention of photography in Europe in the late 1830s and early 
1840s also shares an uncanny historical proximity to the opening up of Japan in 1853 and the subsequent birth of a modern nation state. From the introduction of durable cameras for war photographers to the invention of cameras built into mobile phones, Japan has always been at the forefront of technological invention with regard to photographic technologies. Japan’s cultural and social affinity with photography, and the widespread usage of photography amongst artists as well as amateurs, has had the effect that the cataclysmic events such as the Great Kanto earthquake or the Kobe earthquake of 1995 are so vividly remembered in Japanese society today. In essence, it is the photographic image that is partially responsible for the enduring legacy of these disasters.

As I hope to have illustrated above, Hatakeyama’s photographs of 3.11 feed into a much larger discursive formation where the ethical and moral position of the photographer was hotly debated in Japan. At all times during this debate, Hatakeyama has exhibited a keen awareness of the potential complications of producing artworks, or indeed choosing to photograph the effects of the disaster in the first place. Yet, crucial to Hatakeyama's visual methodology is the fact that his own photographic archive from the region precedes the disaster itself. Here, Hatakeyama does not simply provide a crude 'before' and 'after' juxtaposition, but rather his work must be seen in a larger ontological context where notions such as memory, truth or reality are in themselves questioned through the photographic image. Hatakeyama's photographs of the aftermath of the disaster include, perhaps necessarily, images that were taken many years before the tsunami altered the landscape forever. Hatakeyama thus establishes the fact that places are primarily produced through our memory of these places. Photography, as highlighted in his work, fulfils the crucial function of 
facilitating the mental process of remembering as well as mourning. This approach, in turn, facilitates new ways of thinking that broaden our understanding of social, cultural and natural ecologies. Hatakeyama's work on 3.11 thus must be seen not simply as a series of photographs of the disaster but as a method to theorize and conceptualize the disaster through the act of image making.

\section{Acknowledgements}

The majority of research for this article was conducted during a two-month Japan Foundation Fellowship in the summer of 2013. I would like to thank the Japan Foundation for supporting me throughout this time. I would also like to

thank the Ph.D. candidate Ryosuke Kondoh whose knowledge and understanding of contemporary Japanese art very much guided the direction of the research. Additional thanks got to Sohl Lee who provided very useful feedback on earlier drafts of this article.

\section{References}

Anon. (2011a), Hatakeyama Naoya: Hisaichi to natta kokyō Rikuzentakata wo toru (Naoya Hatakeyama: Photographs the affected area in his hometown Rikuzentakata), Geijutsu Shinchō, November, pp. 125-27. (2011b), 'Satellite photos of Japan, before and after the quake and tsunami', New York Times, 13 March, 
http://www.nytimes.com/interactive/2011/03/13/world/asia/satellite-photos-japanbefore-and-after-tsunami.html? r=0. Accessed 2 January 2016.

Barthes, R. (1981), Camera Lucida - Reflections on Photography, New York: Hill and Wang.

Bohr, Marco (forthcoming), World Cinema and the Essay Film, London: Wallflower Press.

Foster-Rice, G. and Rohrbach, J. (2013), Reframing the New Topographics, Chicago: University of Chicago Press.

Fujiwara, Toshi (2012), Mujin Chitai (No Man’s Zone), DVD, Ennetbaden: Trigon Film.

Goldberg, V. (2015), 'Review: Japanese photographers reflect on the Fukushima Catastrophe', New York Times, 19 June, http://www.nytimes.com/2015/06/20/arts/design/review-japanese-photographers-

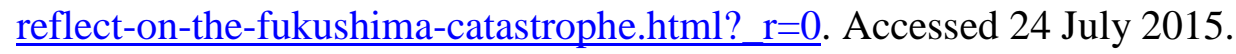

Goto, Yumi (2013), in-person interview, Tokyo.

Hatakeyama, N. (2011a), [untitled article], Asahi Camera, September Issue, pp. 7677. 
(2011b), Bijutsu Techo, December, pp. 192-99.

(2013), Kesengawa, La Madeleine: Light Motiv Editions.

Homma, T. (2011), Mushrooms from the Forest, Tokyo: Blind Gallery.

(2013), 'Eizō no Tsuyosa to Muryokusa, 11 ${ }^{\text {th }}$ of June 2011' ('Symposium on the

Strength and Powerlessness of the Image'), in REF lab. (ed.),Visual Philosophy Note, vol. 1, Tokyo: Gendaikikakushitsu, not paginated.

Ishikawa, N. and Moriyama, D. (2011), 'Sekai e, rojō e!' ('To the world, to the street!'), Eureka: Poetry and Criticism, pp. 43-15.

Kobayashi, K. (2012), Memowāru: Shashinka Furuya Seiichi to no niju nenkan ('Memoir: Twenty years with the Photographer Furuya Seiichi'), Tokyo: Shueisha, pp. 19-20.

Moriyama, D. (2011), ‘An Evening with Daido Moriyama’, Lecture Program, 3

November, Japan Society, https://www.japansociety.org/webcast/an-evening-withdaido-moriyama. Accessed 24 July 2015.

Tran, J. L. (2015), 'The problems and pleasure of publishing the horrors of the 3/11 tsunami', Japan Times, 7 March, 
http://www.japantimes.co.jp/culture/2015/03/07/books/problems-pleasure-publishinghorrors-311-tsunami/. Accessed 24 July 2015.

Weisenfeld, G. S. (2012), Imaging Disaster: Tokyo and the Visual Culture of Japan's Great Earthquake of 1923, Berkeley: University of California Press.

\section{Contributor details}

Marco Bohr is the Postgraduate Programme Director for the Arts at Loughborough University. Originally from Germany, Marco holds a BFA in Image Arts from Ryerson University, Toronto, a Masters of Photography from the Royal College of Art and a Masters in the History of Art with specialism on early Japanese photography from SOAS, University of London. In 2011 Marco was awarded a Ph.D. from the University of Westminster for a theoretical thesis that investigates contemporary Japanese photography. The thesis examines the work of a new generation of female photographers who emerged during the social, economic and political shifts of the post-bubble era (1990-99). Before he joined Loughborough University in 2012, Marco was Visiting Fellow at The Australian National University in Canberra where he taught photography theory and practice. Marco has contributed to a number of edited volumes such as The Contemporary Visual Studies Reader (Elkins et al.), Frontiers of Screen History (Merivirta et al.), On Perfection (Longhurst), the book series Directory of World Cinema and the book series World Film Locations. Marco has also contributed to the Dandelion Journal, the exhibition catalogue for Modernity Stripped Bare held at the University of Maryland and the artist book Kim Jong Il Looking at Things 
published by Jean Boîte Éditions. Marco is on the editorial board for the journal East Asian Journal of Popular Culture.

Contact:

Marco Bohr, School of the Arts, Loughborough University, Epinal Way, Loughborough, LE11 3TU, UK.

E-mail: m.bohr@lboro.ac.uk

Notes

${ }^{1} \mathrm{~A}$ case in point is a series of satellite photographs assembled by the New York Times, which depicts the land before and after it was affected by the tsunami (Anon. 2011b). Similar forms of visual display could also have been found in the Japanese media at the time.

${ }^{2}$ See my forthcoming book chapter on Toshi Fujiwara's work in the edited collection World Cinema and the Essay Film. 